\title{
Dhat Syndrome: Depression, Help-Seeking and Patient Beliefs About Causation and Consequences
}

\section{Sharad Manore ${ }^{1}$, G K Vankar ${ }^{2}$, Sachin Gedam ${ }^{3}$}

Section: Healthcare

Sci. Journal Impact

Factor: 6.1 (2018)

ICV: 90.90 (2018)

(c) (i) (8)

Copyright@IJCRR

\author{
'Associate Professor Department of Psychiatry BRLSABV Memorial Govt Medical College Rajnandgaon (Chhattisgarh), India; ${ }^{2}$ Profes- \\ sor and Head of Psychiatry department, Parul Sewashram Hospital, Limbda, Wagodiya, Vadodara Gujarat, India; ${ }^{3}$ Associate Professor, \\ Department of Psychiatry, Shri Shankaracharya Institute of Medical Science, Bhilai, Chhattisgarh, India
}

\section{ABSTRACT}

Introduction: Dhat syndrome is a culture-bound syndrome seen in the Indian subcontinent and also similar syndrome has been described in another part of the world.

Aims: To explore socio-demographic characteristics, associated depression, prior help-seeking, and beliefs regarding causation and consequences in patients with Dhat syndrome.

Method: Prospective study on 100 patients of dhat syndrome attending Psychiatry department as an outpatient in a tertiary care general hospital in western India. Depression was assessed by the Patient Health Questionnaire (PHQ 9). Patients were interviewed for beliefs about dhat, prior help-seeking, and explanations of dhat offered by the helpers. Patients' views why they have dhat syndrome and opinions about the consequences of dhat syndrome were explored.

Results: The majority were the young adult, migrant workers from neighbouring states with education up to high school, and belonging to lower socioeconomic status. Depression was found in $38 \%$ case. Patients reported a significant decline in sexual functioning after the onset of dhat- 18 had premature ejaculation, 28 had erectile dysfunction and 20 had small penis size as associated complaints. Most patients had consulted non-psychiatry 'experts'- quacks, general practitioners or practitioners of Ayurved/homoeopathy/ Unani, and dermatologist-venereologist. Most patients believed that dhat can cause somatic symptoms are commonly seen in depression as well as sexual dysfunctions.

Conclusion: The study largely confirms the findings of earlier studies on dhat syndrome. A significant proportion of patients are having depression and decline in sexual satisfaction and sexual dysfunctions. They also believe sexual myths often propagated by quacks.

Key Words: Culture-Bound Syndrome, Depression, Dhat Syndrome, Epert, Help-seeking, Sexual Dysfunction

\section{INTRODUCTION}

Culture-bound syndromes have been defined by Littlewood and Lipsedge as 'episodic and dramatic reactions specific to a particular community. ${ }^{1}$ Yap coined the term CultureBound Syndrome(CBS) in 1969, described a rare and exotic group of disorders that cause little damage to humanity; however, they may be unpredictable and chaotic behaviour. Dhat syndrome term coined by N N Wig in 1960 and is considered as a culture-bound syndrome. ${ }^{2}$ Dhat syndrome is more prevalent in the Indian subcontinent. This syndrome includes various somatic, psychological symptoms such as fatigue, weakness, decreased appetite, decreased physical strength, forgetfulness, poor concentration, guilt and other vague somatic symptoms. It is usually associated with anx- ious or dysphoric mood with or without sexual dysfunction. ${ }^{3}$

The word dhat is derived from the Sanskrit word dhatu meaning 'metal' 'elixir'. Since Vedic Indian system of Medicine as well as various religion Hinduism, Muslim, Christian, Buddhism, valued, emphasized and promoted the conservation of semen and these belief maintained by traditional healers who deals with such issues. ${ }^{4}$ Due to widely prevalent belief misattribute physiological changes such as turbidity of urine and tiredness as the passage of semen and amplification of somatic symptoms under stressful condition. ${ }^{5}$ This semen loss disorder not limited to India but also seen in Western European culture since ancient time. In work of Aristotle (384-322 BC) and Galen semen is given importance

\section{Corresponding Author:}

Dr. Sharad Manore, MD, Associate Professor, Department of Psychiatry BRLSABV Memorial Govt Medical College Rajnandgaon (Chhattisgarh), Pin 491441, India, Email: drsharadmanore@gmail.com

ISSN: 2231-2196 (Print)

Received: 04.08 .2020
ISSN: 0975-5241 (Online)

Revised: 18.09 .2020
Accepted: 07.10 .2020
Published: 12.11 .2020 
as 'soul substance' and mentioned physical and psychological effect due to semen loss. ${ }^{6}$ Dhat syndrome-like disorders are described in other countries- Prameha in Sri Lanka, Jiryan in South-East Asia and Shen-k'uei in China. ${ }^{7}$ Grover et al. showed common situations where patients experience the passage of dhat- night emission, passing stool, urination, in sexual excitement and while watching reading pornography. Passage of dhat in this specific guilt-ridden situation may give rise to this syndrome. ${ }^{8}$ In a study by Prakash et al Most common associated symptoms in dhat syndrome were Sense of being unhealthy (99\%), worry (99\%), and feeling that there will be no improvement despite treatment (97\%), tension (97\%), tiredness (95\%), fatigue (95\%), weakness (95\%), and anxiety (95\%). Among sexual complaints, most common were the loss of masculinity $(83 \%)$, erectile dysfunction $(54 \%)$, and premature ejaculation $(53 \%){ }^{9}$

In India traditional healers highly publicize themselves as 'experts in sexology' and propagate sexual myths. ${ }^{10}$ Fear of semen loss and its cure is propagated by advertisement on the wall, television, roadside hoarding, newspaper and by Vaid and Hakim in the most parts of north India ${ }^{3}$. Quacks besides giving their 'formulas' advise patients to take ghee (purified butter), milk, protein-iron rich food, vitamin injections, and getting married marriage as treatments. ${ }^{11,12}$ Various studies found depression as the comorbid illness with prevalence rate varied between $40-66 \%$ and anxiety disorder in $21-38 \%$ cases. ${ }^{3,9,13}$ Somatoform and hypochondriacal disorder in 32 to $40 \%$ of cases with dhat syndrome. ${ }^{3,9,13}$ Psychosexual disorder as comorbid with dhat syndrome- premature ejaculation in $22-44 \%$ and erectile dysfunction, impotence in $22-62 \%$. Other disorders like stress reaction, phobias, obsessive ruminations, depressive psychosis, body dysmorphic symptoms, and delusional disorders are also seen. ${ }^{3,9,13}$

\section{MATERIALS AND METHODS}

This prospective study was conducted at tertiary care hospital Psychiatry outpatient dept. in western India from July 2010 to August 2011. All consecutive patients who presented with the chief complaints of loss of semen through urine, night emission, overindulge sexual activity and masturbation were included in study and diagnosis of Dhat syndrome was considered, based on the International Classification of Diseases (ICD)-10 clinical criteria. ${ }^{14}$

Institutional Ethical Committee approved the study. Those who given written informed consent were included in the study. Those who were younger than 18 years of age and who did not give informed consent were excluded. Those patients whose history and mental status examination suggested Psychosis, Mental retardation, and any organic illness were also excluded. Semi-structured performa was used to document their socio-demographic characteristics. The Pa- tient Health Questionnaire (PHQ-9) the 9-item depression screen in Hindi and Gujarati were applied ${ }^{15}$. Major depression was diagnosed if 5 or more of the 9 depressive symptom criteria were present at least "more than half the days" in the past 2 weeks, and one of the symptoms is depressed mood or lack of interest must be there. One of the 9 symptom criteria "thoughts that you would be better off dead or of hurting yourself in some way" counts if present at all, regardless of duration.

All patients were interviewed for about forty five minutes about their, beliefs about dhat, their sexual experiences, and sexual functioning. Patients were asked to rate their sexual satisfaction on scale of 1 to o $10(1=$ least sexual satisfaction and $10=$ full sexual satisfaction) before and after the onset of their illness. Patients were also interviewed about their treatment seeking, and explanations from whom they consulted. They were also asked about their opinion on 5 point Likert scale (strongly agree, Agree, Not Certain, Disagree and Strongly Disagree), if passing of dhat could cause the following: weakness, body ache, backache, headache, anxiety, low mood, lack of concentration, difficulty in doing work, weight loss, early ejaculation, poor erection.

\section{Statistical analysis}

The data was tabulated, Microsoft excel and Statistical Package for Social Science (SPSS 10) was used for further analysis. Thematic analysis was done for beliefs about that and the past consultant explanation of dhat.

\section{RESULTS}

\section{Demographic characteristics}

Patient age ranged from 18 to 64 with mean age 29.38(sd 9.6) years. 57 were married, 41 were single and 2 were divorced, 77 were Hindus while others followed Islam or Sikhism. Sixty-three had migrated from neighbouring states Rajasthan, Uttar Pradesh, and Madhya Pradesh. Fifty-eight had a rural background, 56 were skilled workers the rest were unskilled workers.

Fifty-nine had completed secondary school education, 37 had primary education and 4 had no formal education, $85 \%$ had a monthly income below Rupees 5000/- suggesting the low socio-economic status

\section{Chief complaints on presentation}

Most of the patients had a chief complaint of weakness (97\%), body ache (46\%), anxiety (29\%), poor erection (28\%), early ejaculation (18\%), low mood and lack of interest $(27 \%)$, weight loss $(25 \%)$, the small size of penis $(20 \%)$.

\section{Depression in Dhat Syndrome}


Depression was present in $38 \%$ of cases, severe depression in $36 \%$ and moderate depression in $2 \%$. As shown in Table 1, PHQ (Patient Health Questionnaire) scale total of score 0 -not at all, 1-several days, 2-More than half of the days, 3-Nearly every day, Sum of 1,2,3. 1 to 4 indicates minimal depression, the score between 5 to 9 indicate Mild depression, 10 to 14 indicate Moderate depression and 15 to 27 indicate moderately severe and severe depression. In this study, $38 \%$ of cases having a score between 15 to 27 and 2\% of cases have a score between 10 to 14 .
At individual item in PHQ 9 symptoms present over more than half of days (1) Little interest present in $41 \%$ cases (2) Feeling down, depressed $39 \%$ case. (3)Trouble falling or staying asleep 38\% (4) Feeling tired or having little energy $52 \%$ (5) Poor appetite 39\% (6) Feeling bad about yourself $38 \%$ (7) Trouble concentrating things 39\% (8) Moving or speaking slowly 38\% (9) Better to dead off $36 \%$ cases over past two weeks.

Table 1: Patient Health Questionnaire Responses of Dhat Syndrome Patients (N=10o)

\begin{tabular}{|c|c|c|c|c|c|}
\hline Item & $\begin{array}{c}\text { Not at all } \\
(0)\end{array}$ & $\begin{array}{l}\text { Several } \\
\text { Days (1) }\end{array}$ & $\begin{array}{l}\text { More than } \\
\text { half (2) days }\end{array}$ & $\begin{array}{l}\text { Nearly every } \\
\operatorname{day}(\mathbf{3})\end{array}$ & $\begin{array}{c}\text { Percentage } \\
(\mathbf{2}+3)\end{array}$ \\
\hline Little interest & 13 & 46 & 9 & 32 & $41 \%$ \\
\hline Feeling down, depressed & 52 & 9 & 17 & 22 & $39 \%$ \\
\hline Trouble falling or staying asleep & 40 & 22 & 18 & 20 & $38 \%$ \\
\hline Feeling tired or having little energy & 2 & 46 & 20 & 32 & $52 \%$ \\
\hline Poor appetite & 31 & 30 & 17 & 22 & $39 \%$ \\
\hline Feeling bad about yourself & 54 & 8 & 21 & 17 & $38 \%$ \\
\hline Trouble concentrating things & 34 & 27 & 21 & 18 & $39 \%$ \\
\hline Moving or speaking slowly & 61 & 1 & 23 & 15 & $38 \%$ \\
\hline Better to dead off & 61 & 3 & 29 & 7 & $36 \%$ \\
\hline
\end{tabular}

Note: Not at all-o, Several days-1, More than half of days-2, Nearly every days-3

\section{Sexual Functioning in Dhat Syndrome}

As shown in Table 2 patient rating of sexual satisfaction declined after the onset of dhat syndrome. All 100 patients $25 \%$ rated $7,47 \%$ rated $8,26 \%$ rated 9 before the onset of dhat syndrome and all 100 patients $38 \%$ rated $1,45 \%$ rated 2 , $16 \%$ rated 3 after the onset of dhat syndrome.

Table 2: Rating of sexual satisfaction by patients $(\mathrm{N}=100)$

\begin{tabular}{|c|c|c|c|c|c|c|c|c|c|c|}
\hline $\begin{array}{l}\text { Sexual Functioning } \\
\text { Rating }\end{array}$ & 1 & 2 & 3 & 4 & 5 & 6 & 7 & 8 & 9 & 10 \\
\hline Before & o & $\mathrm{o}$ & o & o & o & o & 25 & 47 & 26 & 02 \\
\hline After & 38 & 45 & 16 & 01 & o & o & o & o & o & o \\
\hline
\end{tabular}

Before the onset of dhat syndrome, all the patients rated their sexual satisfaction from 7 to 10 , while the same after the illness was from 1 to 4 . Eighteen patients had premature ejaculation, 28 had erectile dysfunction and 20 had small penis size as associated features

\section{Patient Beliefs about dhat}

Most of the patients with dhat syndrome believed dhat as a vital fluid(40\%), source of power and energy(33\%), pro- duced from a large quantity of blood(41\%) and requires nutritious food for the production of semen (27\%). As shown in Table 3, Passage of dhat can cause Weakness $99 \%$, Bodyache 94\% cases, Headache 42\%, Backache $66 \%$, Anxiety 89\%, Lack of Concentration 44\%, Poor memory $68 \%$, Small size of Penis $62 \%$, Poor erection $33 \%$, Early ejaculation $50 \%$, Infertility $53 \%$ 
Table 3: Patient's opinion about the consequences of the passage of dhat $(\mathrm{N}=100)$

\begin{tabular}{lcccccc} 
Symptoms & $\begin{array}{c}\text { Strongly } \\
\text { Agree }\end{array}$ & Agree & Neutral & Disagree & $\begin{array}{c}\text { Strongly } \\
\text { disagree }\end{array}$ & $\begin{array}{c}\text { Percentage } \\
\text { Strongly agree + Agree }\end{array}$ \\
Weakness & 97 & 2 & 0 & 1 & 0 & $99 \%$ \\
Bodyache & 69 & 25 & 1 & 5 & 0 & $94 \%$ \\
Headache & 3 & 39 & 35 & 15 & 8 & $42 \%$ \\
Backache & 35 & 31 & 15 & 19 & 0 & $66 \%$ \\
Anxiety & 68 & 21 & 5 & 6 & 0 & $89 \%$ \\
Lack of concentration & 33 & 11 & 31 & 17 & 8 & $44 \%$ \\
Poor Memory & 35 & 33 & 17 & 12 & 3 & $68 \%$ \\
Small size of penis & 37 & 25 & 26 & 12 & 0 & $62 \%$ \\
Poor erection & 28 & 5 & 38 & 29 & 0 & $33 \%$ \\
Early ejaculation & 18 & 32 & 40 & 10 & 0 & $50 \%$ \\
Infertility & 38 & 15 & 25 & 16 & 0 & $53 \%$ \\
\hline
\end{tabular}

\section{Attribution to sexual experiences}

Sexual history revealed Premarital sex in $48 \%$ cases including $26 \%$ in unmarried and $22 \%$ in married patients, masturbation $(46 \%)$, unprotected $\operatorname{sex}(15 \%)$, extramarital $\operatorname{sex}(13 \%)$, multiple sex partners(2\%) and homosexual activity (1\%). Dhat syndrome patients attribute their illness to masturbation $(30 \%)$, premarital sex $(20 \%)$, unprotected $\operatorname{sex}(15 \%)$ and extramarital sex (7\%). It is interesting to note that all patients with unprotected sex, multiple sex partners and homosexual activity attribute dhat syndrome to those experiences.

\section{Treatment seeking for dhat syndrome}

Most of the patients were advised to seek treatment by friends $(42 \%)$, relatives $(30 \%)$ or wife $(12 \%)$ while $16 \%$ of patients themselves sought help on their own. Treatment was sought from sex quack $(51 \%)$, general practitioner or physician $(30 \%)$, dermatologist and venereologist (15\%). Only 4 patients had the first consultation with a psychiatrist.

The patients were offered following explanations for dhat: excess masturbation (26\%), weakness of nerves of the penis $(15 \%)$, no explanation( $19 \%)$, exposure $(3 \%)$, weakness of $\operatorname{mind}(2 \%)$ weakness of body, constipation, lifting heavyweight, pressure on nerves of the penis, lack of blood in the body, lack of calcium, melting of bone, infection, incurable illness $(1 \%$ each $)$

\section{DISCUSSION}

In this study about Dhat syndrome, age of patients ranged from 18 to 64 years with mean age 29.4 (SD 9.6), most belonged to lower socioeconomic status, had a monthly income below 5000 and were mostly educated up to secondary school, 57 were married and 43 were single, a majority had a rural background. Among 100 patients $70 \%$ cases age were equal to or above 30 years. This indicates young patients were more vulnerable to dhat syndrome as shown in several studies. ${ }^{8,16,17}$ They had a lower education level and belongs to low to medium socioeconomic level. ${ }^{11,16-18}$. However recent multicentric study shows a majority of patients belonged to middle socioeconomic status and this syndrome seen in patients with all educational levels. ${ }^{8}$ Dhat syndrome is commonly seen in unmarried or recently married $^{16}$. In our study, more patients were married than single (57 vs 43). As seen in the study by Sawant and Nath, misconceptions about semen, masturbation, circumcision, and vasectomy widely prevalent in both unmarried and married those who patients living in a city away from their wives in village. ${ }^{19}$ In our study 63 out of 100 patients were migrant from North Indian states and 77 were Hindu by religion. It indicates that dhat syndrome may be more prevalent in North India. In a multicentric study in India by Grover et al. of 780 dhat syndrome patients $51 \%$ cases were from the north and central India and $69 \%$ cases were Hindu by religion. However, the prevalence of Dhat syndrome is not restricted to Hindus but is spread over among all communities of the Indian subcontinent. It has been seen among Sikhs in Punjab, Buddhists in Sri Lanka and Muslims in Pakistan. ${ }^{20}$

In this study, depression was comorbid with dhat syndrome in $38 \%$, severe in $36 \%$ and moderate depression in $2 \%$. Similar findings found in various studies. In the study by Sawant and Nath found $39.4 \%$ of cases having severe depression and $15.1 \%$ cases having extreme depression on Beck Depression Inventory. ${ }^{19}$ Several studies have found comorbid depression from $39.5 \%$ to $66.6 \%$ of patients with dhat syndrome. ${ }^{13,21}$ In the multicentric study of comorbidity with dhat syndrome by Grover et al. found $38.5 \%$ cases of depressive/anxiety disorder including $22.6 \%$ cases of both comorbid sexual dysfunction and depressive/s anxiety disorder. ${ }^{22}$

In-Patient Health Questionnaire 9 (PHQ 9) following symptoms more than half of the days were present over 
past two-week little interest (41\%), feeling down (39\%), trouble falling asleep (38\%), feeling tired (52\%), poor appetite $(39 \%)$, feeling bad about self $(38 \%)$, trouble in concentrating (39\%), moving or speaking slowly (38\%), better to dead off $(36 \%)$. This severity of depression may be due to patients included in study attending to the tertiary care centre and another confirmatory test for depression not applied this is the limitation of our study. So it is necessary to evaluate depression while dealing with this syndrome. Also multicentric study reported little interest $(63.7 \%)$, feeling down (62.4\%), trouble falling sleep (50.8\%), feeling tired(67.9\%), poor appetite(47.8), feeling bad about self (50.4\%), trouble in concentrating(49.1\%), psychological agitation or retardation( $29.9 \%$ ), thought better to dead off $(29.9 \%)^{8}{ }^{8}$

Effect on sexuality due to the passage of dhat, we found a marked decline in sexual functioning after the onset of dhat syndrome. This is similar to multicentric study. ${ }^{8}$ This may influence of Ayurvedic medicine that believes that loss of semen in any form leads to decrease in physical and mental energy as one drop of semen is made up of 100 drops of blood and one drop of blood made from various minerals and nutritious food that ingested by male and it takes a long period to regenerate. ${ }^{23}$ Behere and Natraj (1984) in their series found $26 \%$ of dhat syndrome patients had impotence and $22 \%$ premature ejaculation. Bhatia and Malik (1991) reported an association of Dhat syndrome with impotence and premature ejaculation in $8.3 \%$ and $14.6 \%$ respectively. Chadda and Ahuja (1990) reported that $42.3 \%$ of dhat syndrome patients had premature ejaculation and $36.5 \%$ of patients had erectile dysfunction.

The beliefs shared by patients in this study are similarly Pundhir et al. ${ }^{24}$ In Bhatia Malik study, perceived consequences mentioned were inability to get a male child, malformed fetus, impotency and shrinkage of the penis. ${ }^{11}$ Also in the multicentric study, perceived consequences of passing dhat found early ejaculation, poor erection, reduction in the size of penis reported by $66.4 \%, 62.2 \%$ and $50.8 \%$ cases receptively. ${ }^{8}$ Patients were also inquired about certain specific sexual behaviours and perceived role in dhat syndrome. Though India is a conservative society where sex is never mentioned and is considered a taboo. We found $48 \%$ cases of both single and married, the experience of pre-marital sex, $15 \%$ had unprotected sex, $13 \%$ had extramarital sex, $2 \%$ had multiple sexual partners, $1 \%$ had homosexual activity, and $46 \%$ had the experience of masturbation. Its seems that these figures underreported considering lower social desirability due to social taboos regarding these behaviours, more so in case of masturbation. According to patients, these experiences were responsible for the present condition, 30\% patients attributed it to masturbation, $20 \%$ to premarital sex, $15 \%$ to unprotected sex. $7 \%$ blamed to extramarital and $1 \%$ to homosexual activity.
All the patients $(15 \%)$ who had unprotected sex considered it as a causative factor for dhat syndrome. It indicates more guilt and fear of HIV infection associated with unprotected sex. Further studies are needed to evaluate fear and belief about unprotected sex concerning dhat syndrome. Chadda and Ahuja (1990) mentioned that 24(46.1\%) out of 52 patients consider masturbation, $11(21.1 \%)$ pre or extramarital relation and 3(5.8\%) homosexual complex to causative factor. Bhatia and Malik (1991) mentioned that $45.1 \%$ of their patients blamed to masturbation and excessive sex ${ }^{11}$. Also in study Grover et.al.(2016) $55.1 \%$ cases reported masturbation, $24.5 \%$ to excessive sexual intercourse, $22.7 \%$ to premarital sexual intercourse as a causative factor for dhat syndrome. ${ }^{8}$ It indicates guilt feeling about sexual excitement, masturbation and premarital and extramarital sex. In the treatment of dhat syndrome, these need to be addressed.

In our study, most patients were advised by friends and relatives to seek help. Sumathipala and Mumford also mentioned that patients with dhat syndrome acquired knowledge regarding illness from friends, relative, quack, and general practitioner, roadside advertisements ${ }^{12,20}$. As most people do not get sex education from parents, schools or college, they are vulnerable to seek false knowledge from peer groups, roadside hoardings and a quack. This emphasizes the need for scientific sexuality education in schools, colleges, and communities at large.

Before coming to a psychiatrist, the majority had consulted a quack, general practitioner or a physician (Ayurvedic, Unani, Homeopath, or allopathy doctors, and dermatologyvenereologists). Only 4 patients had consulted psychiatrist directly. The explanations given by earlier consultants were similar to Pundhir et al. ${ }^{24}$ Nashi Khan in one of the largest studies on dhat syndrome reported that $73 \%$ of cases visited an hakim and homoeopath health professional. Alternative medicine people advertise this syndrome as a major health concern. They spread the idea that semen is a very valuable body fluid and its loss leads to many physical and mental problems, especially premature ejaculation and impotence. ${ }^{25}$ Patients attending psychiatry outpatient department were included in this study so the results cannot be generalized to the community or other settings. There would be biases like interview bias, recall bias, nonresponsive selection. Casecontrol studies are needed to clarify if the opinions about the causes and consequences of dhat syndrome are limited to dhat syndrome patients or reflect opinions of the general population.

\section{CONCLUSION}

Depression is frequently associated with dhat syndrome and decline in sexual satisfaction. Misbelief regarding causation and consequences of dhat syndrome was observed. 
So effective psycho-education strategies to counter myths and health professional education about sexuality are urgently needed.

\section{ACKNOWLEDGEMENT}

Authors acknowledge the immense help received from the scholars whose articles are cited and included in references of this manuscript.

\section{Conflict of interest: Nill}

Financial support: Nill

\section{REFERENCES}

1. Lipsedge M, Littlewood R. Transcultural psychiatry. In: Granville-Grosman, editor. Recent advances in clinical psychiatry. 3rd ed. Edinburgh: Churchill Livingstone; 1985.

2. Wig NN. Problems of mental health in India. J Clin Social Psychol (India) 1960;17:48-53.

3. Prakash O. Lessons for postgraduate trainees about Dhat syndrome. Indian J Psychiatry 2007;49(3):208-210.

4. Prakash O, Kar SK, Sathyanarayana Rao TS. Indian story on semen loss and related Dhat syndrome. Indian J Psychiatry 2014;56(4):377-82

5. Ranjith G, Mohan R. Dhat syndrome as a functional somatic syndrome: Developing a socio somatic model. Psychiatry 2006;69(2):142-150.

6. Jadhav S. Dhat syndrome: A re-evaluation. Psychiatry 2004;3(8):14-16.

7. Mehta V, De A, Balachandran C. Dhat syndrome: A reappraisal. Indian J Dermatol. 2009;54(1):89-90.

8. Grover S, Avasthi A, Gupta S, Dan A, Neogi R, Behere PB, et al. Phenomenology and beliefs of patients with Dhat syndrome: A nationwide multicentric study. Int J Soc Psychiatry 2016; 62(I):57-66

9. Prakash S, Sharan P, Sood M. A study of the phenomenology of Dhat syndrome in men in a general medical setting. Indian $\mathrm{J}$ Psychiatry 2016; 58(2):129-141.
10. Paris A. Dhat syndrome: A review. Transcult Psychiatr Rev 1992;29:109-118.

11. Bhatia MS, Malik SC. Dhat syndrome: A useful diagnostic entity in Indian culture. Br J Psychiatry 1991;159(5):691-695.

12. Sumathipala A, Siribaddana SH, Bhugra D. Culture-bound syndromes: The story of Dhat syndrome. Br J Psychiatry 2004; 184:200-209.

13. Deb KS, Balhara YS. Dhat syndrome: A review of the world literature. Ind J Psychol Med 2013;35(4):326-331.

14. World Health Organization. International Statistical Classification of Diseases and Related Health Problems.10th rev. Geneva: World Health Organization: 1992.

15. Kochhar PH, Rajadhyaksha SS, Suvarna VR. Translation and Validation of brief patient health questionnaire against DSMIV as a tool to diagnose the major depressive disorder in Indian patients. J Postgrad Med 2007;53(2):102-107.

16. Behere PB, Natraj GS. Dhat syndrome: The phenomenology of a culture-bound sex neurosis of the orient. Indian J Psychiatry 1984;26(1):76-78.

17. Bhatia M, Bohra N, Malik S. "Dhat" syndrome-a useful clinical entity. Indian J Dermatology. 1989;34:32-41.

18. Nakra BR, Wig NN, Varma VK. A study of male potency disorders. Indian J Psychiatry 1977;19:13-18.

19. Sawant NS, Nath A. Cultural misconceptions and associated depression in Dhat syndrome. Sri Lankan J Psychiatry 2012 :3(1); 17-20.

20. Mumford DB. The 'Dhat syndrome': A culturally determined symptom of depression? Acta Psychiatr Scand 1996;94(3):163167.

21. Dhikav V, Aggarwal N, Gupta S, Jadhavi R, Singh K. Depression in Dhat syndrome. J Sex Med 2008;5(4):841-844.

22. Grover S, Avasthi A, Gupta S, Dan A, Neogi R, Behere PB, et.al Comorbidity in Patients with Dhat Syndrome: A Nationwide Multicentric Study. J Sex Med 2015:12(6):1398-1401.

23. Money J, Prakasam K, Joshi V. Semen conservation doctrine from ancient ayurvedic to modern sexological theory. Am J Psychother. 1991;45(1):9-14

24. Pundhir A, Srivastava RK, Sharma S, Singh P, Joshi HS, Aggarwal V, et al. Dhat Syndrome Assessment Using Mixed Methodology. Asian J Psychiatry 2015;16(2):157-167.

25. Khan N. Dhat syndrome in relation to demographic characteristics. Indian J Psychiatry 2005;47(1):54-57. 